\title{
EFFECT OF DIFFERENT SOURCES OF FIBER ON THE INTESTINAL MORPHOLOGY OF DOMESTIC GEESE
}

\author{
Peter W. S. Chiou', T. W. Lu', J. C. Hsu and B. Yu \\ Department of Animal Sciences, National Chung-Hsing University, Taichung, Taiwan, R.O.C.
}

\section{Summary}

Experiment was conducted to study the effect of sources of dietary fiber on the intestinal morphology of geese. Sixty white Roman geese of two-week-old were divided randomly into six groups and were fed with isoenergetic and isonitrogenous diets which contain alfalfa meal, barley hull, rice hull, purified cellulose, lignin, or pectin as the major dietary source of fiber.

Different sources of dietary fiber significantly influenced the villi height and the crypt depth in the duodenum, and the villi height and the muscle layer thickness in the ileum $(p<0.05)$. The duodenal villus in the geese that fed diets with alfalfa meal, rice hull or pectin supplemented were significantly longest $(968.5 \mu \mathrm{m})$, whereas the lignin group was significantly shortest villus and deepest crypt depth $(\mathrm{p}<0.05)$.

The thicknesses of the ileal and caecal muscle layer were significantly thicker in the geese fed with cellulose supplemented diets than in those fed with the other treatment diets. The caecum of the barley bran fed geese possessed significantly longest villi and the most thick muscle layers $(p<0.05)$.

From scanning electronic microscopic observation, the leafy and plate-like in the duodenal villi morphology of geese represented a more effective nutrient absorption in the small intestine. The morphology of ileal villi in geese was similar from herbivorous rabbit and from the African Green monkey.

(Key Words : Intestinal Morphology, Geese, Dietary Fiber Components)

\section{Introduction}

Effect of dietary fiber on the intestinal morphology of the gallinaceous species depended on its dietary habit. The relationship of the level of dietary fiber and the weight and length of the intestine usually is positively correlated. Miller (1975) found that weights in all segments of intestine increase in millard birds as level of dietary fiber increased. Abdelsamie et al. (1983) showed a length increased in all segments of small intestine in broilers fed an increased level of acid detergent fiber. Hegde et al. (1978) also showed a significance influenced sources of dietary fiber over intestinal length in chicks, and this is also true in goslings as showed by Chen et al. (1992).

' Address reprint requests to Dr. Peter W. S. Chiou, Department of Animal Sciences, National Chung-Hsing University, 250 Kuo-Kuang Road, Taichung, Taiwan, R.O.C.

${ }^{2}$ Department of Animal Sciences \& Technology, National Pingtung Polytechnic Institute, Pingtung, Taiwan.

Received January 9, 1996

Accepted May 9, 1996
Gasaway (1976) regarded this increase in size of caeca to the bulkiness of dietary fiber. These increases in size therefore capacity in volume of the small intestine, may be due to eating a greater quantity than quality of feed (Fenna and Boag, 1974; Savory and Gentle, 1976).

Sources of dietary fiber may also influence length, weights and other morphology of the intestine. Atkinson and Kelsey (1984) examined the effect of diet composition, a high protein diet vs. a high fiber diet, on the intestinal growth of White Pekin ducklings; They found no effect of dietary treatment on their measurements of small intestine, caeca, and large intestine. In contrast, Kehoe and Ankney (1985) proved that the morphological differences in waterfowl guts that reflected dietary differences. They measured caeca length, small intestine length, and gizzard weight from individuals of the five species diving ducks.

Diet with the high fiber supplement, pectin for example, influences the intestinal mucosa of birds; Keshavarz (1986) described a pasty droppings in the pectin diet, and Patel et al. (1980) found an adverse effect 
of performance in chicken fed a pectin diet. Effects of the colloid character of pectin that delay maturity of intestinal mucosal cells in rats (Stanogias and Pearce, 1985), presumably also exist in chickens. Rolls et al. (1978) found an increase in the turnover rates in intestinal mucosal cells of chickens that fed wheat bran. Obviously, sources of dietary fiber influenced growth and turnover rate in the intestinal epithelial cells, therefore capability of nutrients absorption. Chiou et al. (1994) also suggested that different fiber components influence villus height and muscle layer thickness of the jejunum and colon, and influence the crypt depth of the duodenum and ileum in the domestic rabbits. Although, geese like rabbits, both can survive on high fibrous diet by microbial fermentation in hindgut, data in geese is hardly available. This study therefore aims to investigate the effect of the source and component of dietary fiber on the histology and morphology of the various intestinal segments in geese.

\section{Materials and Methods}

Sixty white Roman female goslings of two weeks old were selected, and were randomly allocated into twelve groups of five geese each; Two duplicate groups of goslings were assigned into each treatment. They were housed in wire cages $(110 \times 121 \times 55 \mathrm{~cm})$ for four weeks and were fed experimental diets. Diets were formulated into an isoenergetic and isonitrogenous experimental feeds according to NRC (1984) and are presented in table 1. Feed and water were supplied ad libitum. Diets contained 9\% dietary fiber that was derived mainly from alfalfa meal, barley bran, rice hull, purified cellulose (J. Rettnmaier and Sohne, Arbocel M 80), lignin (Tokyo Kasei Ltd.) or pectin, respectively; the alfalfa supplement was a control diet.

At the end of the feeding experiment, all birds were weighted individually; four geese of each treatment were sacrificed; the intestinal tracts were then removed to measure the weight and length of each intestine segment. The gut segments were cut open along their length and rinsed with saline solution to clean the content; excess fat was removed, and the excess water of the intestine samples was dried by dry tissue paper. The duodenum was measured between the post gizzard and the duodenal loop; while the jejunal and ileum samples were pool together referred as ileum since the different of the two segments was hardly to define (Duke, 1986). An intestine sample of $5 \mathrm{~cm}$ length was taken from every segment of the intestine. A duodenum sample was taken on $8 \mathrm{~cm}$ from the gizzard. An ileum segment was sampled on 20 $\mathrm{cm}$ to the anterior end of the ileal-caecal-colic junction; caecal samples were taken on the middle of the caecum, and the colonic sample was taken on the $8 \mathrm{~cm}$ to the posterior end of the ileal-caecal-colic junction.

Samples were rinsed through $0.4 \mathrm{M} \mathrm{KCl}$ solution first and were then placed into a $10 \%$ buffered neutral formaldehyde solution ( $\mathrm{pH}$ 7.2-7.4). All samples were gradually dehydrated through an increasing concentration of the ethyl alcohol (50\%-100\%). These specimens were embedded in paraffin first, and samples were then prepared by sectioned at $6 \mu \mathrm{m}$ and were stained with hematoxylin and eosin. The intestinal histology was measured according to Hampson (1986). The villi height was measured by averaging the height of the ten intact villi. A crypt depth was measured by averaged of 30 measurements. Muscle layer thickness was calculated by averaging the 20 locations of muscle layers.

Samples prepared for the SEM were according to the method of Paulini et al. (1987) that was modified method of Moore et al. (1988). All gut samples were fixed initially in $10 \%$ buffered neutral formaldehyde; then the specimens were fixed again by placing in $0.1 \mathrm{M}$ phosphate buffer of $\mathrm{pH} 7.3$ three times with $10 \mathrm{~min}$; Samples were then placed in $1 \%$ osmium tetroxide overnight. These samples were then rinsed in a phosphate buffered solution four times with $15 \mathrm{~min}$. Then, samples were gradually dehydrated by increasing alcohol concentrations: $50,70,80,90$, and $95 \%$ for-10-15 min. The concentration was then increased to $100 \%$ for dehydration samples three times; these were then dried, mounting on aluminum stubs and coated with gold for 30 min, and then placed in the SEM (Bausch \& Lomb Ltd. Nonolab 2100) for scanning.

All data were analyzed by using the general linear models procedure of statistical analysis system (SAS, 1985). Significant differences among treatments were figured out by Duncan's multiple range test.

\section{Results}

The mean daily feed intake and the average daily gains were alfalfa meal 183 and 87 , barley bran 172 and 75 , rice hull 187 and 87 , cellulose 186 and 85 , lignin 200 and 83, and pectin 155 and $71 \mathrm{~g} /$ bird, respectively. Dietary sources of fiber significantly influenced the feed intake and weight gain $(p<0.05)$. Geese that were fed diets with natural source of fiber, i.e., alfalfa or rice hull, gained the best body weight and converted feed best; Although these results were only significantly different from those of the pectin diet. The geese in the pectin group ate the least and gained the least weight. Geese in the lignin group although they ate more feed compared to the other 
TABLE 1. INGREDIENT COMPOSITION OF THE EXPERIMENTAL DIETS

\begin{tabular}{|c|c|c|c|c|c|c|}
\hline \multirow{2}{*}{ Ingredients } & \multicolumn{6}{|c|}{ Treatment } \\
\hline & Alfalfa meal & Barley bran & Rice hull & Cellulose & Lignin & Pectin \\
\hline & \multicolumn{6}{|c|}{ 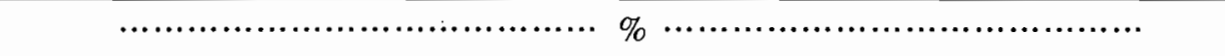 } \\
\hline Yellow corn & 39.08 & 30.59 & 40.88 & 52.79 & 52.81 & 52.81 \\
\hline Soybean oil meal & 7.40 & 6.06 & 13.26 & 26.90 & 26.94 & 26.94 \\
\hline Full fat Soybean & 19.31 & 28.81 & 23.50 & 5.34 & 5.30 & 5.30 \\
\hline Fish meal $(60 \%)$ & 3.00 & 3.00 & 3.00 & 3.00 & 3.00 & 3.00 \\
\hline Alfalfa meal & 25.88 & - & - & - & - & - \\
\hline Barley bran & - & 25.28 & - & - & - & - \\
\hline Rice hull & - & - & 13.21 & - & - & - \\
\hline Cellulose & -- & - & - & 5.95 & - & - \\
\hline Lignin & - & - & - & - & 5.93 & - \\
\hline Pectin & - & - & - & - & - & 5.93 \\
\hline Soybean oil & 3.00 & 3.00 & 3.00 & 3.00 & 3.00 & 3.00 \\
\hline Dicalcium phosphate & 1.11 & 1.31 & 1.29 & 1.05 & 1.05 & 1.05 \\
\hline Calcium carbonate & - & 0.60 & 0.62 & 0.82 & 0.82 & 0.82 \\
\hline Salt & 0.40 & 0.40 & 0.40 & 0.40 & 0.40 & 0.40 \\
\hline DL-methionine & 0.20 & 0.24 & 0.18 & 0.17 & 0.17 & 0.17 \\
\hline Choline chloride & 0.12 & 0.21 & 0.16 & 0.08 & 0.08 & 0.08 \\
\hline Premix $^{1}$ & 0.50 & 0.50 & 0.50 & 0.50 & 0.50 & 0.50 \\
\hline Total $(\%)$ & 100 & 100 & 100 & 100 & 100 & 100 \\
\hline
\end{tabular}

Analyzed value

Crude protein

G. E. $(\mathrm{kca} / \mathrm{kg})$

Crude fiber (\%)

$\mathrm{NDF}(\%)$

ADF (\%)

Cellulose $(\%)$

AD-Lignin (\%)

$\begin{array}{cc}20.70 & 20.83 \\ 4,611 & 4,552 \\ 9.4 & 9.3 \\ 27.2 & 30.6 \\ 13.9 & 11.3 \\ 10.1 & 10.2 \\ 1.8 & 2.1\end{array}$

20.27
4,548
9.0
27.2
13.6
9.9
2.7

20.18
4,546
6.4
27.3
13.5
9.4
2.1
20.08
4,499

2.9

14.1

5.9

4.6

1.3

\footnotetext{
${ }^{1}$ Premix components per kg of diet: Vit. A 25,00a IU; Vit. $D_{3} 5,000 \mathrm{IU}$; Vit. E $38 \mathrm{mg}$; Vit. $\mathrm{K}_{3} 0.01 \mathrm{mg}$; Vit. $\mathrm{B}_{1} 5 \mathrm{mg}$; Vit. $\mathrm{B}_{2} 2.5$ mg; Vit. $B_{6} 5 \mathrm{mg}$; Vit. $\mathbf{B}_{12} 0.025 \mathrm{mg}$; Folic acid $1.25 \mathrm{mg}$; Biotin $2.5 \mathrm{mg}$; Niacin $0.1 \mathrm{mg}$; Ca-pantothenate $0.03 \mathrm{mg}$; Cu $15 \mathrm{mg} ; \mathrm{Mn} 80$ $\mathrm{mg}$; Fe $70 \mathrm{mg}$; $70 \mathrm{mg}$; Zn $100 \mathrm{mg}$; Co $0.5 \mathrm{mg}$; Se $0.15 \mathrm{mg}$.

${ }^{2}$ Calculated nutrient value of the diets, $\%$ : Crude protein $20.00 \%$; M. E. $2,900 \mathrm{kcal} / \mathrm{kg}$; Crude fiber $9.00 \%$; Calcium $0.83 \%$; Total phosphorus 0.64\%; Available phosphorus $0.41 \%$.
}

treatment groups, they did not however show significantly better feed conversion.

\section{The weight and length of intestinal segments}

Effects of dietary fiber on the length and weight of the geese intestinal segments are presented in table 2. Sources of dietary fiber did not significantly influence the intestinal length of various segments except colon where the intestine was significantly longer in the group of cellulose and lignin $(p<0.05)$, and a significantly shorter in the rice hull group $(\mathrm{p}<0.05)$.
Converting these figures into the relative length of the ratio to the body length, both segments of the duodenum and colon were significantly influenced by the dietary treatment. The relative lengths of the duodenum in the barley bran and the cellulose group were significantly longer; while the pectin group was significantly shortest among the treatment groups $(p<0.05)$. Conversely, a different picture in the colon was shown that a significantly longer in the barley bran, the cellulose and the lignin group; whereas a significantly shorter in the alfalfa meal and the rice hull group was presented $(p<$ 
0.05). The fresh weights of the duodenum, the ileum and the colon showed statistically significant differences among the treatment groups. All small intestine segments that included duodenum and ileum, were significantly heavier in the groups of the rice hull and the lignin $(\mathrm{p}<0.05)$, where the barley bran group was significantly lighter $(p<0.05)$. The fresh weight of the colon did not show the same trend; lignin and the pectin groups were significantly heavier, and the barley group was significantly lighter in the colon $(p<0.05)$; rectum and colonic boundary of birds were short and were hardly distinct; length of this intestinal segment was less than 10 $\mathrm{cm}$ in birds including Peking duck, broilers and Leghorn (Isshiki et al., 1992). Our measurement of the length in the rectal-colonic of geese thought was only $12.3 \mathrm{~cm}$ in average, and was longer than other species of birds.

TABLE 2. EFFECT OF DIFFERENT SOURCES OF DIETARY FIBER ON PERFORMANCE AND INTESTINAL TRACTS OF 5 WEEKS OLD GOSIINGS

\begin{tabular}{|c|c|c|c|c|c|c|c|}
\hline Item & $\begin{array}{l}\text { Alfalfa } \\
\text { meal }\end{array}$ & $\begin{array}{c}\text { Barley } \\
\text { bran }\end{array}$ & $\begin{array}{l}\text { Rice } \\
\text { hull }\end{array}$ & Cellulose & Lignin & Pectin & $\begin{array}{c}\text { Standard } \\
\text { error }\end{array}$ \\
\hline \multicolumn{8}{|l|}{ Duodenum } \\
\hline Length & 35.18 & 35.38 & 34.10 & 37.68 & 34.78 & 33.83 & 1.31 \\
\hline Relative length & $65.30^{\mathrm{ab}}$ & $73.23^{\mathrm{a}}$ & $68.06^{\mathrm{ab}}$ & $72.72^{\mathrm{a}}$ & $69.43^{\mathrm{ab}}$ & $64.25^{\mathrm{b}}$ & 2.59 \\
\hline Weight & $15.44^{\mathrm{ab}}$ & $12.02^{\mathrm{b}}$ & $16.70^{\mathrm{a}}$ & $13.91^{\mathrm{ab}}$ & $15.28^{\mathrm{a}}$ & $14.25^{\mathrm{ab}}$ & 0.99 \\
\hline Relative weight & 0.53 & 0.45 & 0.52 & 0.45 & 0.46 & 0.51 & 0.03 \\
\hline \multicolumn{8}{|l|}{ Ileum $^{1}$} \\
\hline Length & 182.04 & 174.43 & 173.43 & 92.34 & 187.03 & 131.53 & 7.45 \\
\hline Relative length & 337.21 & 360.48 & 346.44 & 372.32 & 373.49 & 344.17 & 14.16 \\
\hline Weight & $65.17^{\mathrm{ab}}$ & $53.31^{\mathrm{b}}$ & $75.31^{\mathrm{a}}$ & $61.87^{\mathrm{ab}}$ & $71.23^{\mathrm{a}}$ & $63.45^{a b}$ & 6.22 \\
\hline Relative weight & 2.26 & 2.02 & 2.35 & 2.02 & 2.33 & 2.24 & 0.22 \\
\hline \multicolumn{8}{|l|}{ Caecum } \\
\hline Length & 50.83 & 51.88 & 50.73 & 53.98 & 51.70 & 52.20 & 2.86 \\
\hline Relative length & 94.42 & 106.95 & 101.36 & 104.26 & 103.30 & 99.42 & 5.88 \\
\hline Weight & 7.38 & 7.73 & 8.31 & 7.08 & 9.69 & 7.04 & 0.92 \\
\hline Relative weight & 0.25 & 0.29 & 0.26 & 0.23 & 0.29 & 0.25 & 0.03 \\
\hline \multicolumn{8}{|l|}{ Colon } \\
\hline Length & $11.25^{\mathrm{ab}}$ & $12.90^{\mathrm{ab}}$ & $9.75^{\mathrm{b}}$ & $14.20^{\mathrm{a}}$ & $13.78^{\mathrm{a}}$ & $11.93^{\mathrm{ab}}$ & 0.78 \\
\hline Relative length & $20.87^{b}$ & $26.71^{a}$ & $19.46^{\mathrm{b}}$ & $27.56^{\mathrm{a}}$ & $27.51^{\mathrm{a}}$ & $22.63^{\mathrm{ab}}$ & 1.60 \\
\hline Weight & $7.37^{\mathrm{ab}}$ & $5.85^{b}$ & $7.23^{\mathrm{ab}}$ & $6.87^{\mathrm{ab}}$ & $9.15^{\mathrm{a}}$ & $9.44^{\mathrm{a}}$ & 0.83 \\
\hline Relative weight & $0.26^{\mathrm{ab}}$ & $0.22^{b}$ & $0.22^{\mathrm{b}}$ & $0.23^{b}$ & $0.27^{\mathrm{ab}}$ & $0.34^{\mathrm{a}}$ & 0.03 \\
\hline
\end{tabular}

\section{Histology measurement}

The intestinal histology measurements of 5-week-old goslings are presented in table 3 . Averaged villi heights of the segments were following: duodenum $812 \mu \mathrm{m}$, ileum $884.6 \mu \mathrm{m}$, caecum $246 \mu \mathrm{m}$ and colon $978 \mu \mathrm{m}$, respectively. Villi height was tallest in the colon, and was shortest in the caecum; the villi height was quite high and uniform through the small intestine tract, from duodenum to ileum where the most active digestion and absorption take place. From tabel 3, the sources of dietary fiber showed a significant influence in villi height of various intestinal segments $(p<0.05)$ except in the colon. Villi of the duodenum was significantly taller in the groups of the alfalfa, rice hull and the pectin compared to the lignin supplement group $(p<0.05)$, while villi in the ileum was significantly longer in the groups of the alfalfa, lignin and pectin supplement than the other groups $(p<0.05)$. Villi heights of the caecum, on the other hand, were higher in 
barley bran, lignin, and pectin groups than the other groups $(p<0.05)$. The height of the caecal villi in the alfalfa group was found significantly shortest among all treatment groups $(p<0.05)$ in this experiment. From table 3, it showed a crypt depth decrease from duodenum to caecum and then increase to the colon. Effect of the different sources of dietary fiber on the intestinal crypt depth was significant $(p<0.05)$. Crypts were significantly deepest in the group of lignin $(p<0.05)$, and were significantly shortest in the group of cellulose in the duodenum $(p<0.05)$. This trend of the treatment effect in the caecum was also observed.

TABLE 3. EFFECT OF DIFFERENT SOURCES OF DIETARY FIBER ON THE INTESTINAL HISTOLOGY OF 5 WEEKS OLD GOSLINGS, $\mu \mathrm{m}$

\begin{tabular}{|c|c|c|c|c|c|c|c|}
\hline Item & $\begin{array}{l}\text { Alfalfa } \\
\text { meal }\end{array}$ & $\begin{array}{l}\text { Barley } \\
\text { bran }\end{array}$ & $\begin{array}{l}\text { Rice } \\
\text { hull }\end{array}$ & Cellulose & Lignin & Pectin & $\begin{array}{c}\text { Standard } \\
\text { error }\end{array}$ \\
\hline \multicolumn{8}{|l|}{ Duodenum } \\
\hline Villi height & $968.5^{\mathrm{a}}$ & $778.2^{\mathrm{ab}}$ & $873.3^{\mathrm{a}}$ & $806.4^{\mathrm{ab}}$ & $593.9^{b}$ & $850.0^{\mathrm{a}}$ & 29.69 \\
\hline Crypt depth & $334.9^{\mathrm{ab}}$ & $332.5^{\mathrm{ab}}$ & $338.8^{\mathrm{ab}}$ & $274.4^{\mathrm{b}}$ & $404.4^{\mathrm{a}}$ & $313.7^{\mathrm{ab}}$ & 15.48 \\
\hline Muscle thickness & 340.9 & 340.1 & 329.1 & 321.5 & 398.3 & 323.6 & 11.30 \\
\hline Villi/crypt & $2.92^{\mathrm{a}}$ & $2.44^{\mathrm{ab}}$ & $2.66^{\mathrm{a}}$ & $3.06^{\mathrm{a}}$ & $1.51^{\mathrm{b}}$ & $2.81^{\mathrm{a}}$ & 0.51 \\
\hline \multicolumn{8}{|l|}{ Ileum } \\
\hline Villi height & $968.7^{a}$ & $787.5^{\mathrm{b}}$ & $810.5^{\mathrm{b}}$ & $742.3^{b}$ & $994.1^{a}$ & $1,004.4^{\mathrm{a}}$ & 27.64 \\
\hline Crypt depth & 219.3 & 201.4 & 189.2 & 168.8 & 188.4 & 151.7 & 12.14 \\
\hline Muscle thickness & $516.7^{\mathrm{ab}}$ & $434.3^{\mathrm{b}}$ & $712.5^{\mathrm{ab}}$ & $855.3^{\mathrm{a}}$ & $556.4^{\mathrm{ab}}$ & $696.5^{\mathrm{ab}}$ & 51.63 \\
\hline Villi/crypt & $4.43^{b}$ & $3.95^{\mathrm{b}}$ & $4.49^{b}$ & $4.46^{\mathrm{b}}$ & $5.41^{\mathrm{ab}}$ & $6.63^{\mathrm{a}}$ & 0.23 \\
\hline \multicolumn{8}{|l|}{ Caecum } \\
\hline Villi height & $197.9^{\mathrm{b}}$ & $300.3^{\mathrm{a}}$ & $229.9^{\mathrm{ab}}$ & $227.6^{\mathrm{ab}}$ & $260.2^{\mathrm{a}}$ & $258.1^{\mathrm{a}}$ & 21.71 \\
\hline Crypt depth & $148.5^{\mathrm{ab}}$ & $167.5^{\mathrm{a}}$ & $153.8^{\mathrm{a}}$ & $120.9^{b}$ & $165.2^{\mathrm{a}}$ & $155.4^{\mathrm{a}}$ & 6.00 \\
\hline Muscle thickness & $182.0^{\mathrm{a}}$ & $259.7^{\mathrm{b}}$ & $202.1^{\mathrm{ab}}$ & $216.0^{\mathrm{ab}}$ & $217.2^{\mathrm{ab}}$ & $188.2^{\mathrm{a}}$ & 14.76 \\
\hline Villi/crypt & 1.35 & 2.40 & 1.52 & 1.86 & 1.65 & 1.69 & 0.06 \\
\hline \multicolumn{8}{|l|}{ Colon } \\
\hline Villi height & $1,038.9$ & 879.9 & $1,053.6$ & 998.3 & 866.6 & $1,033.1$ & 42.59 \\
\hline Crypt depth & 221.0 & 245.9 & 194.0 & 215.7 & 227.4 & 254.8 & 13.54 \\
\hline Muscle thickness & 233.3 & 241.5 & 221.3 & 252.0 & 230.1 & 234.8 & 7.42 \\
\hline Villi/crypt & 4.89 & 3.94 & 5.47 & 5.34 & 3.88 & 4.19 & 0.31 \\
\hline
\end{tabular}

${ }^{a b}$ Means within the same row without the same superscript are significantly different $(p<0.05)$.

The muscle layer was almost twice thicker in the ileum than in the duodenum in geese with averaging of $342 \mu \mathrm{m}$ and $629 \mu \mathrm{m}$ and becoming thinner in caecum; the muscular layer of the colon was a little bit thicker than caecum; it was $236 \mu \mathrm{m}$ and $210 \mu \mathrm{m}$, respectively. This is different from chicken that the colonic muscle is thicker than that of the intestine anterior to it. From the thickness of the ileal and caecal muscle layer, it showed the thickness of the muscle in the order of ileum, duodenum, colonic, and caecum; it also showed a significant effect of the sources of dietary fiber $(p<0.05)$ on the muscle layer; in the ileum, the muscle layer was significantly thicker in the group of cellulose than in the group of barley bran supplemented; whereas, in the caecal muscle layer was significantly thicker in the group of barley bran supplemented than in the groups of alfalfa or pectin supplemented $(\mathrm{p}<0.05)$. A thicker muscle layer in the intestine may represent a stronger muscular tonic contraction.

\section{Morphological changes}

Morphological changes in duodenum, ileum, caecum and colon of goslings fed with various sources of dietary fibers are presented in figures $1,2,3$ and 4 ; respectively. 

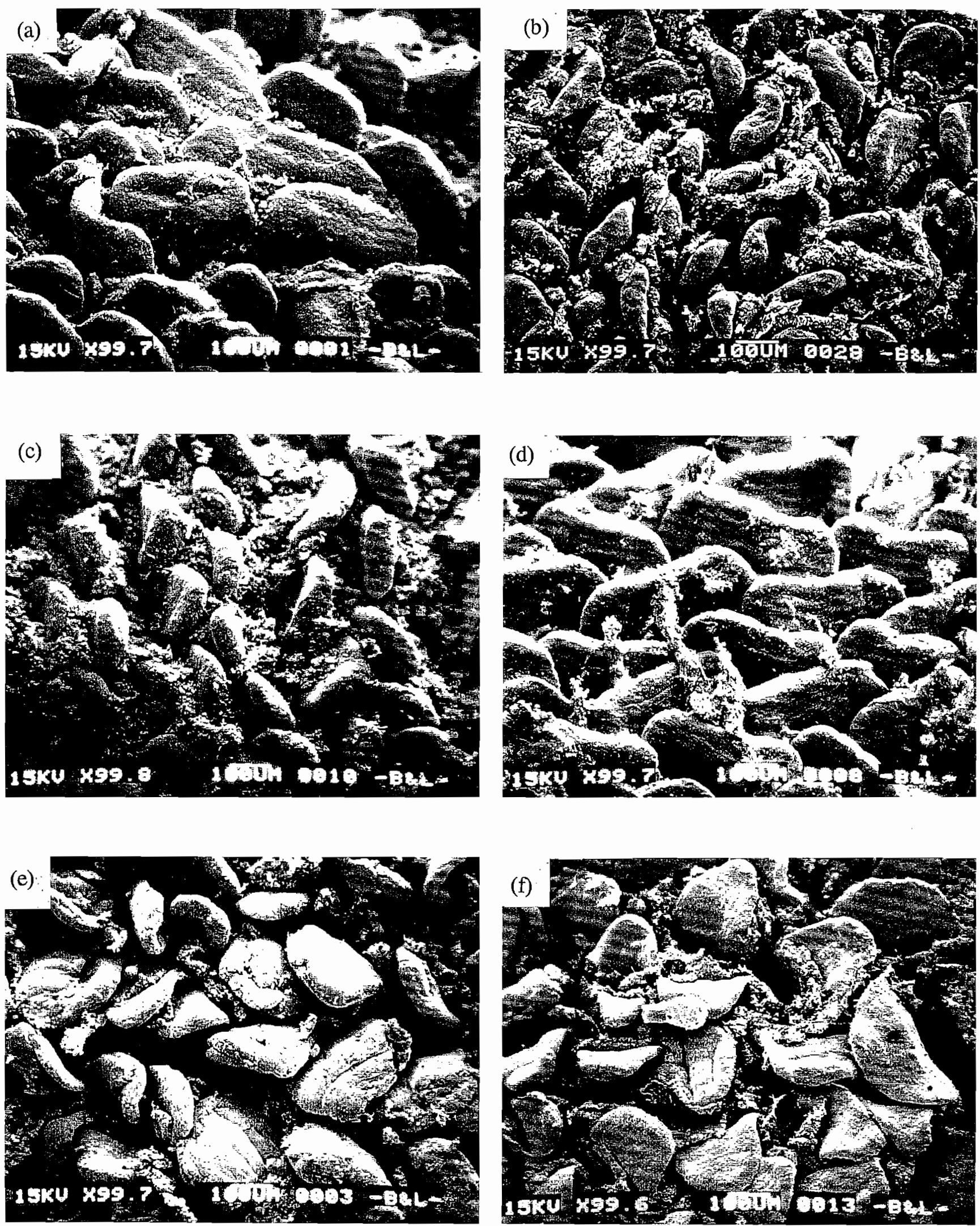

Figure 1. Effect of different sources of dietary fiber on deodenal morphology of the goslings (a) alfalfa, (b) cellulose, (c) barley bran, (d) lignin, (e) rice hull, (f) pectin. 

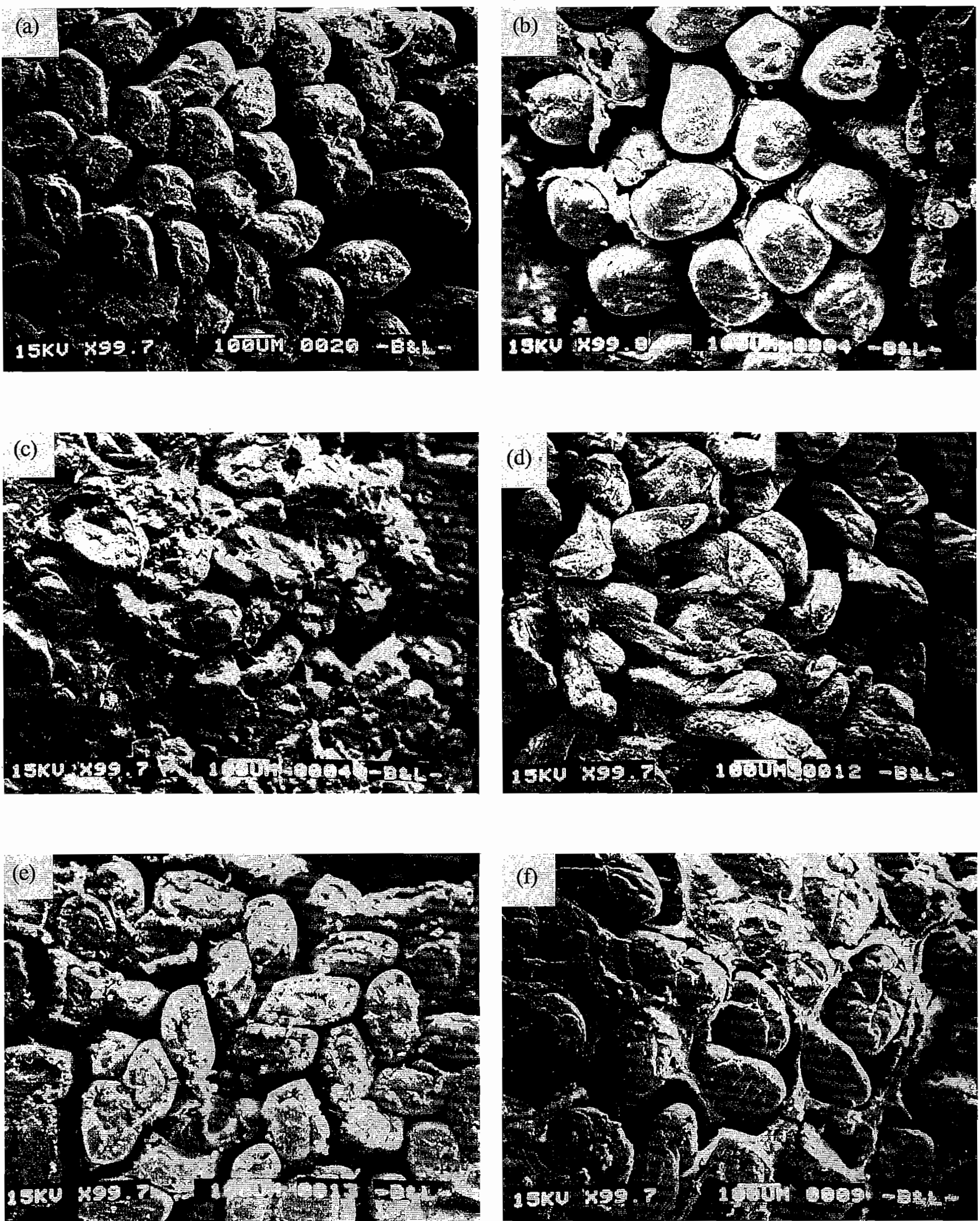

Figure 2. Effect of different sources of dietary fiber on ileal morphology of the goslings (a) alfalfa, (b) cellulose, (c) barley bran, (d) lignin, (e) rice hull, ( $f$ ) pectin. 

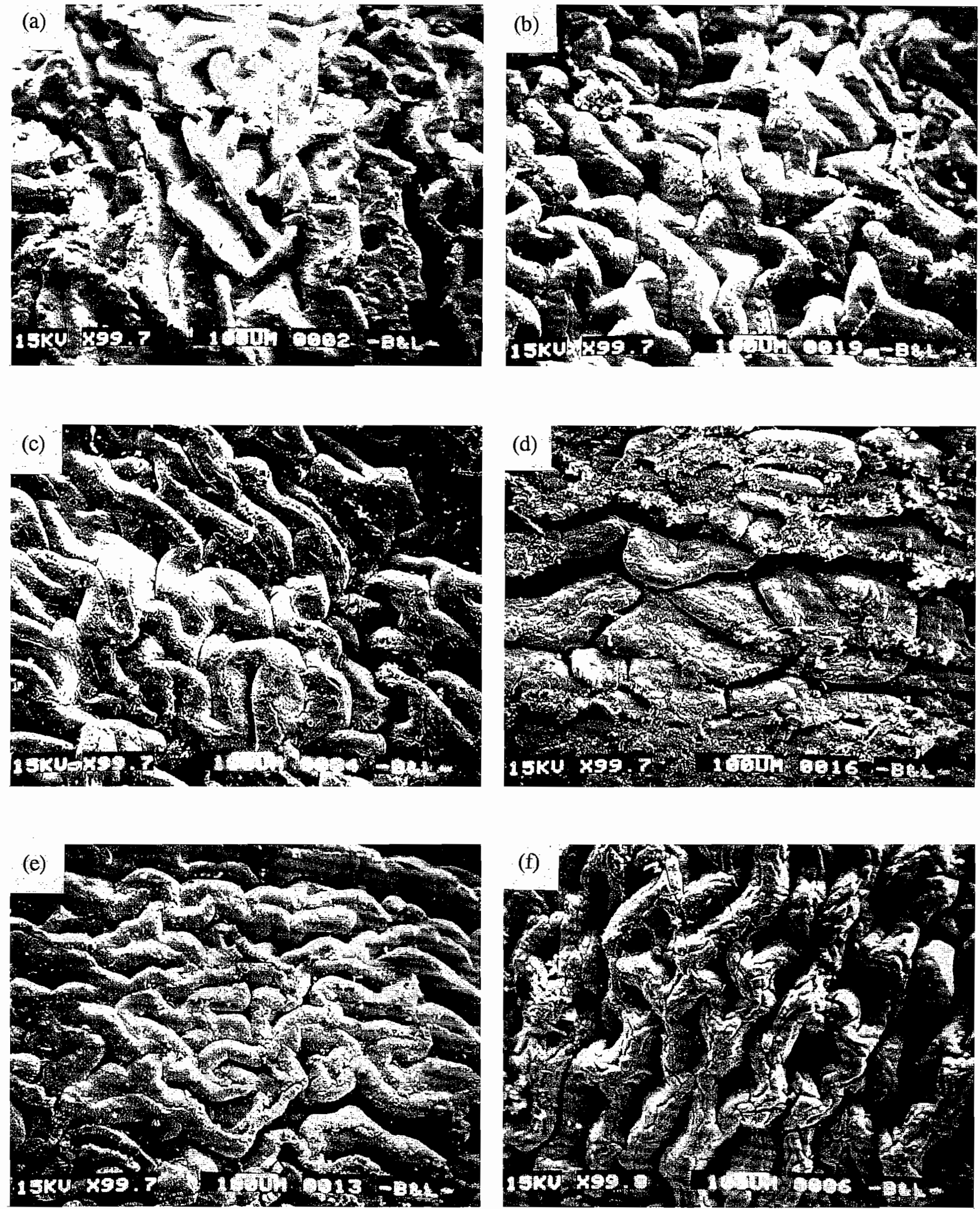

Figure 3. Effect of different sources of dietary fiber on caecal morphology of the goslings (a) alfalfa, (b) cellulose, (c) barley bran, (d) lignin, (e) rice hull, (f) pectin. 

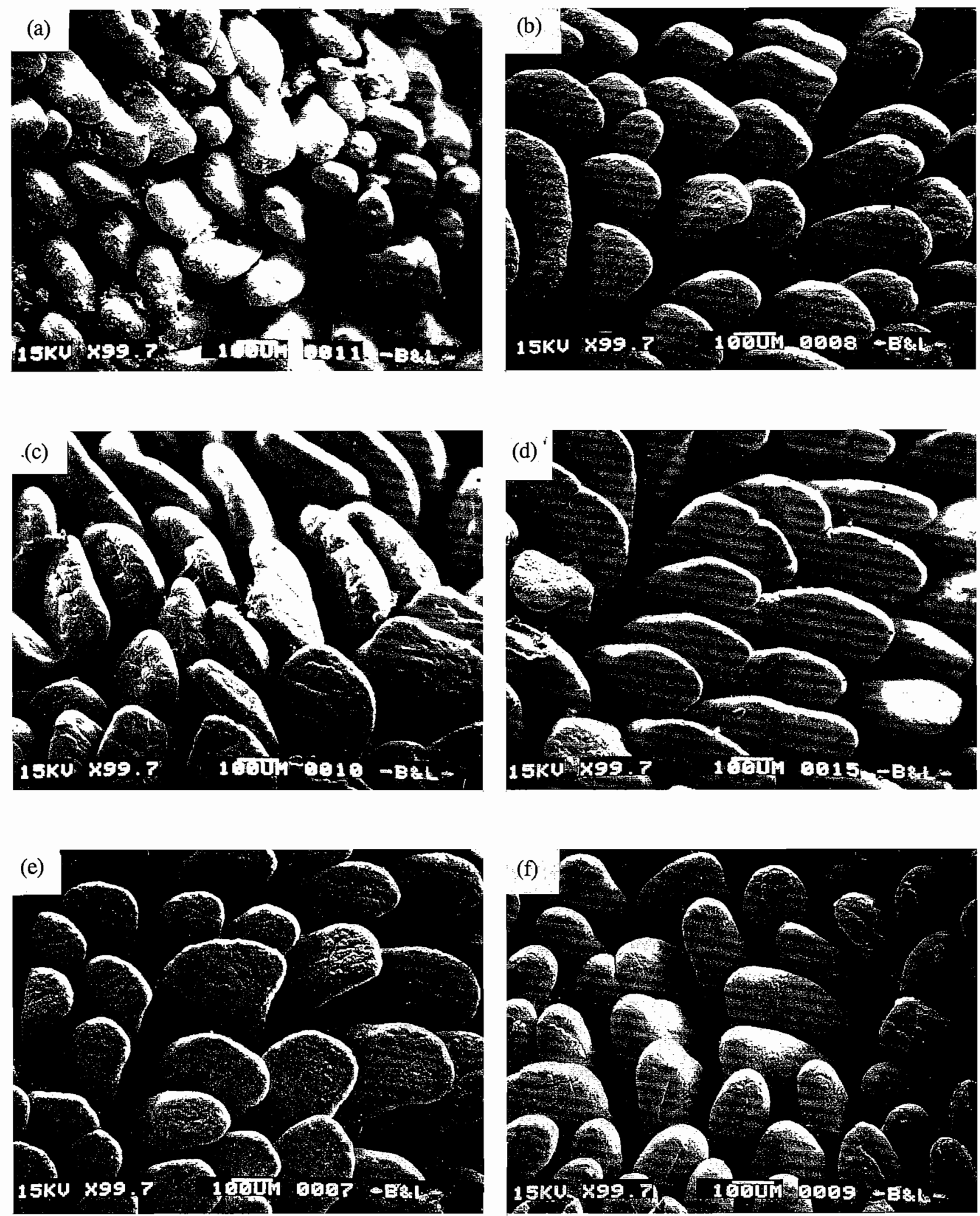

Figure 4. Effect of different sources of dietary fiber on colonic and rectal morphology of the goslings (a) alfalfa, (b) cellulose, (c) barley bran, (d) lignin, (e) rice hull, (f) pectin. 
It was a $100 \mathrm{X}$ magnified pictures of electronic microscopic scanning. When compared the intestinal morphology in different segments, it showed a round tip and leafy type villi in the duodenum, a rod sharp villi in the ileum, a short dense arrangement and folded apparently in caecal villi, and a clear tongue sharp feature in the colon.

From the smoother surface of villi in figure 1 , it showed that the different sources of dietary fibers did not damage the duodenal villi in geese. From the SEM photographs in figure 2, it however, did show a damaged ileal villi in the geese fed with the alfalfa meal or the rice hull. On the other hand, it displayed a fibrous material, i.e., mucin that presumably affixed to the surface of the ileal villi in the pectin and barley bran group. From the SEM photographs of caecal villi, it showed a different surface compared to the other segment of intestine; for example, the villi was merged and forming a fold sharp surface except the group of lignin. It also showed a caecal and rectal-colonic villi damage in the SEM photographs of geese fed with lignin supplemented diet (figure 3 and figure 4). The damage was quite similar to the damage of ileal villi; it also showed some loss of cellular integrity at the apex of villus. No any other impacts of the dietary source of fiber on caecal and colonic mucosa were observed. The villi in caecum showed more narrower folds than the other treatment groups while the lignin group ranked intermediately.

\section{Discussion}

In the most active digestive site of the intestine, the functional digestive unit consists of villi and crypt (Holmes and Lobley, 1989). A shrinkage villi decreases the area of active absorption in the intestine. An increase in crypt depth decreased the activities of enzymes that secreted from tips of the villi (Hampson, 1986). An increased rate of cells turnovers resulted in decreased number of the cell maturities in some normal functional cells, and therefore decreased absorption. The absorptive function therefore may be reflected from the ratio of villi height to crypt depth in the small intestine. Ratios measured in this study were significantly smaller in the duodenum of the lignin group $(p<0.05)$ and showed a lower trend in the barley bran supplemented groups. Conversely, the ratio was significantly higher in the pectin group than in both duodenum and ileum $(p<0.05)$. These implicated that villi in the lignin may be damaged due to the particulate of insoluble fiber, caused an increase in the rate of cells turnover, a decrease of villi height, or an increase in the creep depth of the duodenum.
In feeding different sources of dietary fibers to guineapig, Knehans and O'Dell (1980) found a different degree of damage in the intestinal villi of guinea-pig. They also found that the degree of damage was negatively correlated to the degree of the hydrolysis in dietary fiber. Clemens et al. (1975) displayed a retrograde movement of the particulate marker from the duodenum to ventriculus and proventriculus, however, they did not found retrograde movement of the particulate marker that moved from cloaca to the colon, caecum and distal third of the small intestine. The particulate of the insoluble and indigestible lignin may be retrograde from duodenum to proventriculus that may accelerate the mechanical damage of the mucosal cells. It did show a trend, if did not reach the significant level, of a thicker muscular layer of the duodenum in the lignin group. This suggested possible increases of peristaltic and retrograde movements in the duodenum of the lignin-fed geese that increase the rate of digesta passage, therefore increase the intake of feed in the lignin supplement geese. The severe damaged caecum and colonic mucosa but not the duodenum were observed in this goose trial of the lignin group (figures 3 and 4). This controversial to the expected result may be due to the fast rate of cells turnover in the duodenum, since the increase in cells slaughtering may also increase the rate of turnover. Whether this rapid turnover rate of the tissue cells prevented the damage outlook in the surface of the duodenal villi required further investigation.

Stimulation of cell division was mediated through a fiber's effect on hydrogen ion concentration that produced in the caecum and the other material as bile acids, shortchain fatty acids produced in the colon (Lupton et al., 1988). A trend of shorter colonic mucosa height in the lignin and barley bran groups was observed in this trial $(p$ $<0.05$, table 3). From the SEM photographs, it also showed a damage caecal and colonic villi in the geese fed with lignin supplemeted diet (figures 3 and 4).

Contrary to the insoluble fiber, the soluble dietary fiber usually is more susceptible to becoming colloid state after reaching the duodenum. Dietary fiber of barley bran is more soluble than alfalfa and rice hull, whereas pectin is completely soluble. The colloidal nature of the dietary fiber that limited the dispersion of digestive products, will prevent the digesta from contact absorptive surface, and slow down the rate of passage. A reduced intake of feed due to the prolongation of stomach emptying (Tovar et al., 1989), probably resulted in poor performance of geese in this trial. Johnson et al. (1984) suggested that dietary fiber with the mark different in physical properties, may also differ with the effect of the physiological function; these functional differences are at least partial mediated by the 
effect on mucosal cell proliferation.

Most soluble dietary fiber, i.e., pectin, although process a taller villi in duodenum, ileum, and caecum. However the ratio of villi height to: the creep depth also remained significantly higher in the pectin group (table 3 ). This implicates that soluble fiber did not adverse impact on digestive function. Clemens et al. (1975) observed a retrograde movement of the fluid marker in the intestine tract of geese that moved from the cloaca to the colon, cecum and distal third of the small intestine, where the particulate marker showed no retrograde movement in these segments of tract. They concluded that like that of the rabbits, the cecum of geese selectively retains fluids vs. particulate material and provides the major site for microbial digestion.

It appeared that the villus of the alfalfa and the pectin groups were consistently taller in the small intestine, duodenum and ileum, where the most absorption takes place. It is not clear that the taller villi is due to the turnover rate decrease or the decrease mechanical damage in the alfalfa or pectin supplement. This results agreed with data obtained from herbivorous rabbits fed alfalfa diet (Chiou et al., 1994).

Dietary fiber may stimulate multiplication of mucosal epithelial cells and increase the mucosal secretion. Martin (1990) found that several sulfomucin secreting cells, i.e., goblet cells, increased in the ileum and colon of the pectin treated animals; whereas the goblet cells increased in the middle and the distal end of the colon in cellulose treated animals.

The morphological finding of leafy and plate-like villi in the duodenum of geese was similar to the description of Ziswiler and Farner (1972); they displayed a different villi morphology from the herbivorous birds to the fingerlike villi of the carnivorous birds. Yamauchi and Isshiki (1991) showed a finger-like villi in the small intestine of day-old chicks and white Leghom; some plate-like or wave-like villus were developed in the duodenum or jejunum of the 30-day-old chickens. They also suggested a more effective nutrient absorption in the small intestine with plate-like villi. From the similar micrographs of Yamauchi and Isshiki (1991), it showed that the ileal villi developed a low and narrowtongue like ileal villi in the 10-day-old chicks; While from our trial, it showed a rod sharp in geese (figure 2). The morphology of ileal villi also presented similar apparent from herbivorous rabbit (Chiou et al., 1994) and from the African Green monkey (Paulini et al., 1987).

\section{Acknowledgement}

The authors thank the National Science Council in Taiwan, Republic of China, for financial support of this project. The project number is NSC 82-0409-B005-070.

\section{Literature Cited}

Abdelsamie, R. E., K. N. P. Ranaweera, W. E. Nano. 1983. The influence of fiber content and physical texture of the diet on the performance of broilers in the tropics. British Poultry Science 24:383-390.

Atkinson, J. L. and E. Kelsey. 1984. Effects of diet composition on the development of gut morphology in growing duckings. Poultry Science 63:56. (Supplement).

Chen, Y. H., J. C. Hsu and B. Yu. 1992. Effects of dietary fiber levels on growth performance, intestinal fermentation and cellulase activity of goslings. Journal of The Chinese Animal Science 21:15-28 (in Chinese).

Chiou, P. W. S., B. Yu and C. Lin. 1994. Effect of different components of dietary fiber on the intestinal morphology of domestic rabbits. Comparative Biochemistry and Physiology 108A: 629-638.

Clemens, E. T., C. E. Stevens and M. Southworth. 1975. Sites of organic acid production and pattern of digesta movement in the gastrointestinal tract of geese. Journal of Nutrition 105:1341-1350.

Duke, G. E. 1986. Alimentary canal: anatomy, regulation of feeding and motility. in: Sturkie, P. D. (Ed.) Avian Physiology 4th edn, pp. 269-288 (New York, SpringerVerlage).

Fenna, L. and D. A. Boag. 1974. Adaptive significance of the caeca in Japanese quail and spruce grouse. Canadian Journal of Zoology 52:1577-1584.

Gasaway, W. C. 1976. Seasonal variation in diet, volatile fatty acid production and size of the cecum of rock ptarmigan. Comparative Biochemistry and Physiology 54A: 109-114.

Hampson, D. J. 1986. Alteration in piglet small intestinal structure at weaning. Research in Veterinary Science 40:32-40.

Hedge, S. N., B. A. Rolls, A. Turvey and M. E. Coates. 1978. The effects of chicks of dietary fibre from different sources: a growth factor in wheat bran. British Journal of Nutrition 40:63-69.

Holmes, R. and R. W. Lobley. 1989. Intestinal brush border revisited. Gut 30:1667-1678.

Isshiki, Y., M. Chiuko and Z. Zhou. 1992. The apparent differences of the post-natal intestinal tract development between chicken and water fowls. Proceeding of Japanese Poultry Science 29:150-154. 
(in Japanese).

Jacobs, L. R., J. R. Lupton. 1984. Effect of dietary fibers on rat large mucosal growth and cell proliferation. American Journal of Physiology 246:G378-G385.

Johnson, I. T., J. M. Gee and R. R. Mahoney. 1984. Effect of dietary supplements of guar gum and cellulose on intestinal cell proliferation, enzyme levels and sugar transport in the rat. British Journal of Nutrition 52:477-487.

Kehoe, F. P. and C. D. Ankney. 1985. Variation in digestive organ size among five species of diving ducks (Aythya spp.). Canadian Journal of Zoology 63:2339-2342.

Keshavarz, K. K. 1986. Poultry feed formulation, feeding management must receive utmost consideration. Poultry Digest. 46:176-180.

Knehans, A. W. and B. L. O'Dell. 1980. Intestinal microflora in the guinea pig as observed by scanning electron microscopy, effect of fibrous dietary supplements. Journal of Nutrition 110:1543-1554.

Lupton, J. R., D. V. Coder and L. R. Jacobs. 1988. Longterm effects of fermentable fibers on rat colonic $\mathrm{pH}$ and epithelial cell cycle. Journal of Nutrition 118: 840-845.

Martin, P. A. 1990. Digestion in sheep of diets containing naked oats or barley. Journal of Scientific Food Agriculture 52:477-487.

Miller, M. R. 1975. Gut morphology of mallards in relation to diet quality. Journal of Wildlife Management 39:168-173.

Moore, R. J., E. T. Komegay, R. L. Grayson and M. D. Lindemann. 1988. Growth, nutrient utilization and intestinal morphology of pigs fed high fiber diets. Journal of Animal Science 66:1570-1579.

NRC. 1984. Nutrient requirements of Poultry. 8th ed. (Washington, D.C., National Academy press).
Patel, M. B., M. S. Jami and J. McGinnis. 1980. Effect of gamma iradiation, penicillin and/or pectin enzyme on chick growth depression and fecal stickiness caused by rye, citrus pectin and guar gum. Poultry Science 59:2105-2110.

Paulini, I., T. Metha and A. Hargis. 1987. Intestinal structural changes in African green monkeys after long term psyllium or cellulose feeding. Journal of Nutrition 117:253-266.

Rolls, B. A., A. Turvey and M. E. Coates. 1978. The influence of the gut microflora and of dietary fibre on epithelial cell migraton in the chick intestine. British Journal of Nutrition 39:91-99.

SAS Institute. 1985. SAS User's Guide 5th ed. (Cary, NC., SAS Institute, Inc.).

Savory, C. J. and M. J. Gentle. 1976. Changes in food intake and gut size in Japanese quail in response to manipulation of dietary fiber content. British Poultry Science 17:571-580

Stanogias, G. and G. R. Pearce. 1985. The digestion of fibre by pigs. I. The effects of amount and type of fibre on apparent digestibility, nitrogen balance and rate of passage. British Joumal of Nutrition 53:513 530.

Tovar, J., I. Bjorck and N. G. Asp. 1989. On the nutritional properties of starch and dietary fiber in cassava bread. Nutrition Reports International 39:1237-1246.

Yamauchi, K. E. and Y. Isshiki. 1991. Scanning electron microscopic observations on the intestinal villi in growing white Leghorn and broiler chickens from 1 to 30 days of age. British Poultry Science 32:67-78.

Ziswiler, V. and Farner, D. S. 1972. Digestion and digestive system. in: Farber, D. S. and J. R. King. (eds.) Avian Biology Vol. Il, p. 343 (London, Academic Press). 